\title{
Rheological Properties of Six Plant-Based Seed Gums
}

\author{
Yongbo Chang1, Yifei Li², Quanquan Miao', Huanshi Jiang1, Xin Gao ${ }^{1 *}$ \\ ${ }^{1}$ College of Food Science and Engineering, Ocean University of China, Qingdao, China \\ ${ }^{2}$ Qingdao No.58 High School, Qingdao, China \\ Email: *xingao@ouc.edu.cn
}

How to cite this paper: Chang, Y.B., Li, Y.F., Miao, Q.Q., Jiang, H.S. and Gao, X. (2017) Rheological Properties of Six Plant-Based Seed Gums. American Journal of Analytical Chemistry, 8, 690-707.

https://doi.org/10.4236/ajac.2017.811051

Received: September 18, 2017

Accepted: November 5, 2017

Published: November 8, 2017

Copyright ( 92017 by authors and Scientific Research Publishing Inc. This work is licensed under the Creative Commons Attribution International License (CC BY 4.0).

http://creativecommons.org/licenses/by/4.0/

(c) (i) Open Access

\begin{abstract}
The rheological properties of six mucilage solutions (Guar Gum, Locust Bean Gum, Tamarind Gum, Flaxseed Gum, Artemisia Sphaerocephala Krasch Gum and Cassia Gum) have been examined. It was found that all six gums could be classified into three different types according to the changes of viscosity with increasing shear rate. Steady shear viscous properties in a range of shear rate from 0.1 to $100 \mathrm{~s}^{-1}$ were investigated in the provision of mucilage concentration, $\mathrm{pH}$, temperature and salts. A non-Newtonian shear-thinning behavior was observed. The data of viscosity-shear successfully correlated Power law model. Apparent viscosity was apparently dependent on mucilage concentration increasing significantly as mass fraction went up. A marked dependence of viscosity on temperature was also observed; as temperature increased, the viscosity decreased sharply. The value $\mathrm{n}$ of flaxseed gum is minimum, which means it behaves the greatest shear-thinning properties. Both Guar gum and Tamarind gum possessed better acid-proof and alkali-proof advantages. The flow activation energy of ASKG is $4.3 \mathrm{kcal}$ which is higher than other gums so that the influence of temperature on characteristics of viscosity is stronger. The mechanical spectra in the linear viscoelasticity region were studied in the temperature range from $20^{\circ} \mathrm{C}$ to $90^{\circ} \mathrm{C}$, at a frequency range from 0.1 to $10 \mathrm{~Hz}$. It was observed that Both elastic modulus $\mathrm{G}^{\prime}$ and viscous modulus $\mathrm{G}^{\prime \prime}$ behaviors were found to be dependent on temperature and frequency. What have been investigated in this work could provide guidance for practical application in the field of food industry.
\end{abstract}

\section{Keywords}

Plant-Based Seed Gums, Rheological Properties, Viscosity Behavior, Storage Modulus, Loss Modulus 


\section{Introduction}

Natural gums are polysaccharides consisting of multiple sugar units linked together to large molecules. They have diverse applications as thickeners, emulsifiers, viscosifiers, sweeteners etc. [1]. The term "gum" is used to describe a group of naturally occurring polysaccharides that come across widespread industrial applications due to their ability either to form the gel or make the viscous solution or stabilize the emulsion systems [2]. Nowadays, due to the rapid rise in the consumption of ready-made meals and novelty foods, the use of gums in food products is steadily increasing [3]. Hence, there has been increased interest studying on the physical and functional properties of gums.

The natural gums are categorized based on their origins, behaviors and chemical structures. Gums are known as complex polysaccharides from various sources, e.g. plant seeds, plant exudates, tree or shrub exudates, sea weed extracts, bacteria, and animal sources [4]. A large number of plants can produce the complex polysaccharides commercially known as "plant-based gums" [5]. Plant gums are the polysaccharides originated from various parts of plant. There are a large number of plant species that are being "cultivated" and capable of producing gums which can be implemented in the food industry as additives [6]. Plant gums have more advantages than the other gum from animal and microbial sources, due to the friendly image toward consumers [7]. Recently, there has been increased interest in the physical and functional properties of plant gum exudates and seed gums [8]. From the earliest years until now, hydrophilic polymers of plant seeds are essential for the well-being of humankind, especially as a source of food and medication [9]. The most popular gums utilized in different fields are mainly extracted from plant seeds.

Food gums are used in many formulations for their viscosity-imparting effect on aqueous media, providing acceptable texture to food products [10]. All these properties result from a balance between water-gum interactions and intermolecular, which could be demonstrated by its rheological properties. Previous researchers have studied the rheological properties of a few plant-based seed gums such as guar gum [11], locust bean gum [12]. However, these researches lack comprehensive study of rheological properties of plant-based seed gums such as temperature sweep and the elements influencing its rheological properties. What's more, the study of analyzing the reason causing different rheological properties between various plant-based seed gums hasn't conducted. Thus, the rheological properties of six plant seed gum polysaccharides were studied.

According to the factors of popularity, application, price and commercial values, we selected six plant-based seed gums (Guar Gum, Locust Bean Gum, Tamarind Gum, Flaxseed Gum, Artemisia Sphaerocephala Krasch Gum and Cassia Gum) to explore the generality and particularity between various plant-based seed gums so as to attain the desired functional properties as well as to provide guidance for practical application in the process of food production.

In this work, we comprehensively studied the rheological properties of six 
plant-based seed gums.

The aim of this research is to demonstrate the different rheological properties of Guar Gum, Locust Bean Gum, Tamarind Gum, Flaxseed Gum, Artemisia Sphaerocephala Krasch Gum and Cassia Gum for their further application in food industry.

\section{Materials and Methods}

\subsection{Materials and Sample Preparation}

The dry powders of six plant-based seed gums (Guar Gum, Locust Bean Gum, Tamarind Gum, Flaxseed Gum, Artemisia Sphaerocephala Krasch Gum and Cassia Gum) were purchased from Hennan Huayue chemical products Co., Ltd. (China). Aqueous solutions of six plant-based seed gums were prepared by carefully adding the required amount of dry powder into a vortex formed by mixing with a mechanical stirrer continuously for $30 \mathrm{~min}$ at a constant temperature of $60^{\circ} \mathrm{C}$. After stirring, the samples were stored at $25^{\circ} \mathrm{C}$ for $4 \mathrm{~h}$ for further hydration. Then, the samples were stored at $4^{\circ} \mathrm{C}$ to prevent degradation due to bacterial growth. All tests were completed within $24 \mathrm{~h}$ after sample preparation.

\subsection{Rheological Measurements}

Rheological measurements of the six plant-based seed gums were performed using MCR101 (Austria) rheometer with parallel plate measurement system. The temperature was controlled by a water bath connected to the Peltier system in the bottom plate. A steel cone geometry ( $50 \mathrm{~mm}$ diameter, $47 \mu \mathrm{m}$ gap) was chosen for the rheological measurements. The rheological measurements include steady-state rheology analysis, effects of concentration, temperature, $\mathrm{PH}$, salt on viscosity and dynamic rheological experiment. Three replicates are carried out in the experiments.

\subsubsection{Steady-State Rheology Analysis}

The flow curves of the six plant-based seed gum samples were studied at $25^{\circ} \mathrm{C}$ over the shear rate range of $0.1-100 \mathrm{~s}^{-1}$ to measure the apparent viscosity. This shear rate range covers the flow of a number of non-Newtonian fluid foods in many food operations [13]. The steady-state relationship between shear stress and shear rate of food materials is expressed in terms of Power law model:

$$
\tau=k^{\gamma n}
$$

where $\tau$ is the shear stress $(\mathrm{Pa}), \gamma$ is the shear rate $\left(\mathrm{s}^{-1}\right), K$ is consistency index (Pa.Sn), and $n$ is the flow behavior index(dimensionless).

Power Law fluids can be subdivided into three different types of fluids based on the value of their flow behavior index: $n<1$ pseudoplastic fluid or shear-thinning fluids, $n=1$ Newtonian fluid (where apparent viscosity is constant regardless of imposed stress) and $n>1$ dilatant or shear thickening fluids.

\subsubsection{Effect of Concentration on Viscosity}

The effect of concentration on apparent viscosity of each gum was measured by 
steady shear rheological measurements in concentrations of $0.1 \%, 0.3 \%, 0.5 \%$, $1 \%, 1.5 \%$ and $2 \%(\mathrm{w} / \mathrm{w})$ respectively. Averages of three repeat experiments were considered for data analysis.

\subsubsection{Effect of Temperature on Viscosity}

Solution samples were loaded onto the plate of the rheometer and were equilibrated at $20^{\circ} \mathrm{C}$. The samples were then heated from $20^{\circ} \mathrm{C}$ to $90^{\circ} \mathrm{C}$ at a rate of $5^{\circ} \mathrm{C} / \mathrm{min}$. The relationship of viscosity with temperature of fluid food is taken to satisfy the Arrhenius relationship:

$$
\eta=\eta_{0} \mathrm{e}^{(E a / R)}
$$

where, $\eta_{0}$ is the frequency factor $(\mathrm{Pa} \cdot \mathrm{Sn})$, Ea represents the activation energy (KJ/mol), $R$ is the gas law constant $(R=8.314 \mathrm{~J} / \mathrm{mol} \cdot \mathrm{K})$, and $T$ is the absolute temperature $(\mathrm{K})$. The flow activation energy is calculated using the Arrhenius equation.

\subsubsection{Effect of pH on Viscosity}

The initial $\mathrm{pH}$ values of the solutions were adjusted to $2,4,6,8,10$, and 12 for each sample by adding either $\mathrm{HCl}(0.1 \mathrm{~mol} / \mathrm{L})$ or $\mathrm{NaOH}(0.1 \mathrm{~mol} / \mathrm{L})$ when required. Then, the apparent viscosity was tested at $25^{\circ} \mathrm{C}$. Each sample was measured in triplicate to ensure quantitative accuracy.

\subsubsection{Effect of Salt on Viscosity}

To study the effect of salt on viscosity of gums, the amounts of $\mathrm{NaCl}, \mathrm{CaCl}$ were added at a range of $0.2-2 \mathrm{~g} / \mathrm{dl}$ and completely dissolved as well. All tests were performed at $25^{\circ} \mathrm{C}$. Three replicates were carried out in the experiments.

\subsection{Dynamic Rheological Experiment}

The viscosity properties of food are determined by the dynamic rheological experiment. $G^{\prime}$ is storage modulus expressing the elastic of food, loss modulus G" expresses the viscous of food. The experiments were performed at least in triplicate. Loss tangent $\tan \delta=\mathrm{G}^{\prime \prime} / \mathrm{G}^{\prime}$.

\subsubsection{Temperature Sweep Measurements}

Solution samples were loaded onto the plate of the rheometer and were equilibrated at $20^{\circ} \mathrm{C}$. The samples were then heated from $20^{\circ} \mathrm{C}-90^{\circ} \mathrm{C}$ at a rate of $5^{\circ} \mathrm{C} / \mathrm{min}$ and held at $90^{\circ} \mathrm{C}$ for $20 \mathrm{~min}$ and then cooled to $20^{\circ} \mathrm{C}$. These cooled samples were equilibrated at 20 for $10 \mathrm{~min}$. The tests were performed at a frequency of $1 \mathrm{~Hz}$. The amplitude of the strain in these tests was selected to be $1 \%$ according to the strain sweep results (date not shown) in order to be within the linear viscosity region.

\subsubsection{Frequency Sweep Measurements}

The frequency sweep tests were performed at $25^{\circ} \mathrm{C}$ over the angular frequency range of $0.1-10 \mathrm{rad} / \mathrm{s}$. The strain amplitude for the frequency sweep measurements was selected as $1 \%$. 


\subsubsection{Time Sweep Measurements}

The time sweep tests were measured at $25^{\circ} \mathrm{C}$ at the range of $0 \mathrm{~s}-2000 \mathrm{~s}$ to observe the complex modulus changes. The strain amplitude was selected to be $1 \%$ in the linear viscosity region.

\subsection{Statistical Analysis}

All the experiments were performed on triplicate samples and values were expressed as mean values $\pm \mathrm{SD}$. Differences between mean values were conducted using the one-way analysis of variance (ANOVA) by SPSS 19.0 software. Differences were statistically significant at $\mathrm{p}<0.05$.

\section{Results and Discussion}

\subsection{Steady-State Rheology Analysis}

As shown in Figure 1. The apparent viscosity of all the samples decreases with increasing shear rate, which show that all the samples have shear-thinning behaviors at different levels. This phenomenon could be caused by the disruption of molecular entanglements with the increase of shear rate. Similar observations were reported by Amira et al. [14] and Yong W et al. [15]. This behavior could be related to the variety, $\mathrm{M} / \mathrm{G}$ ratio or difference in molecular weight. It was reported that a solution's viscosity mainly depends on its molar mass [16]. The Flaxseed gum and Locust bean gum samples show the highest apparent viscosity throughout the whole shear rate range in, followed by Guar gum and Tamarind

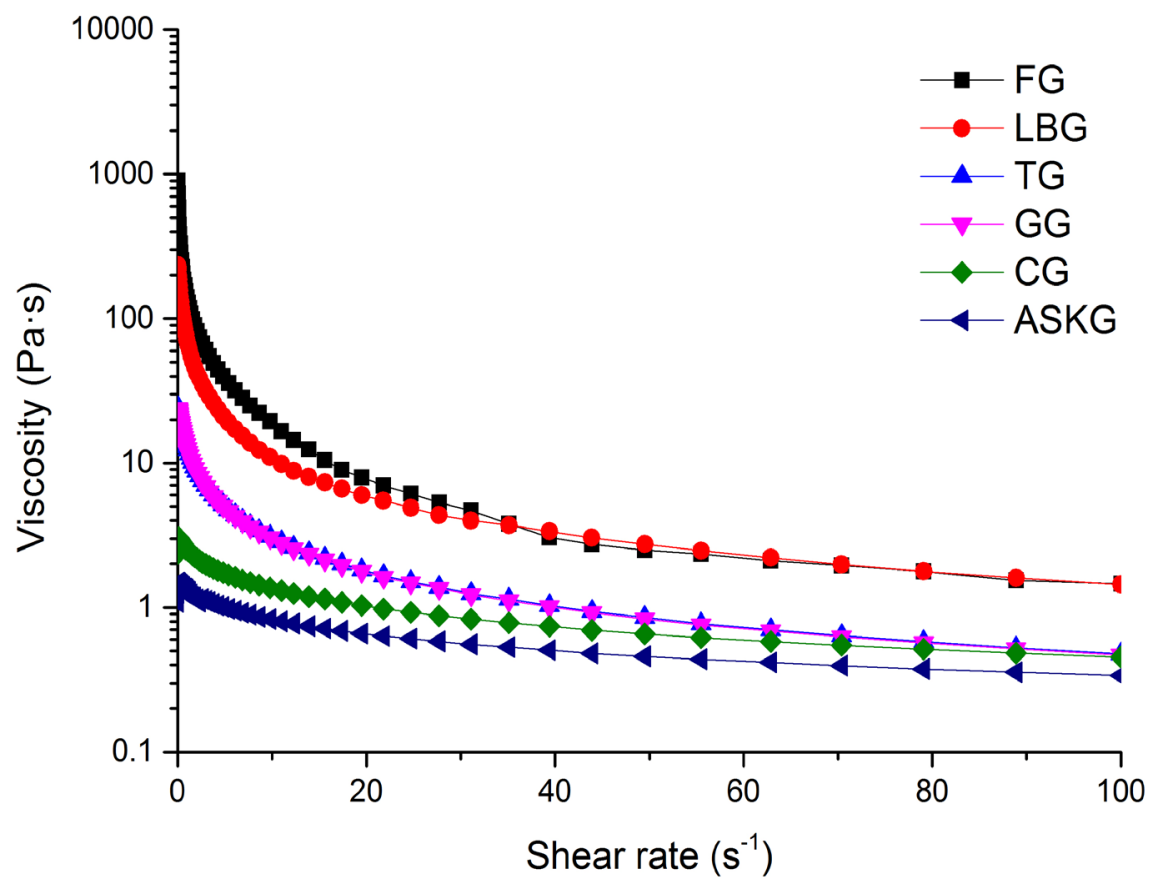

Figure 1. Apparent viscosity flow behavior for six gum solutions versus shear rate ramps $\left(1 \% \mathrm{w} / \mathrm{w}, 25^{\circ} \mathrm{C}\right)(\mathrm{FG}$-fuar gum, LBG-locust bean gum, TG-tamarind gum, GG-guar gum, CG-cassia gum, ASKG-artemisia sphaerocephala krasch gum). 
gum. The Artemisia Sphaerocephala Krasch gum and Cassia gum were the least viscous. This means the first two varieties could behave higher viscous at low concentration. Based on the flow curve of six-plant based gums, they could be subdivided into three different types, which can be considered during the process of ready-food production. Thus, the Flaxseed gum and Locust bean would have an advantage in the provision of viscosity.

The difference of apparent viscosity between six-plant seed gums is mainly related to their Molecular weight as well as the ability to interact with water to form molecular entanglements. The flaxseed gum consists of protein, polysaccharides which include rhamnose, xylose and galactose [17]. So, the high apparent viscosity of flaxseed gum could be expected due to the presence of protein in polysaccharides increased the viscosity of the protein-polysaccharides mixture solution.

The plot of the shear stress versus shear rate is shown in Figure 2, which indicates that the flow behavior of six plant-based gum solutions can be described by a non-Newtonian profile characterized by an index less than 1 (thinning fluid). The shear thinning region of the flow curves were fitted to Power Law model and the rheological parameters for viscosity are shown in Table 1 . The $K$ value is a reflection of the apparent viscosity and the $n$ value is the reflection of the shear-shinning properties [18]. The results indicates that the flaxseed gum solution has the highest $K$ value and the lowest $n$ value, which means that the sample has the highest viscosity and the greater shear-thinning properties at concentration of 1\%. While Artemisia Sphaerocephala Krasch gum has the lowest $K$ value

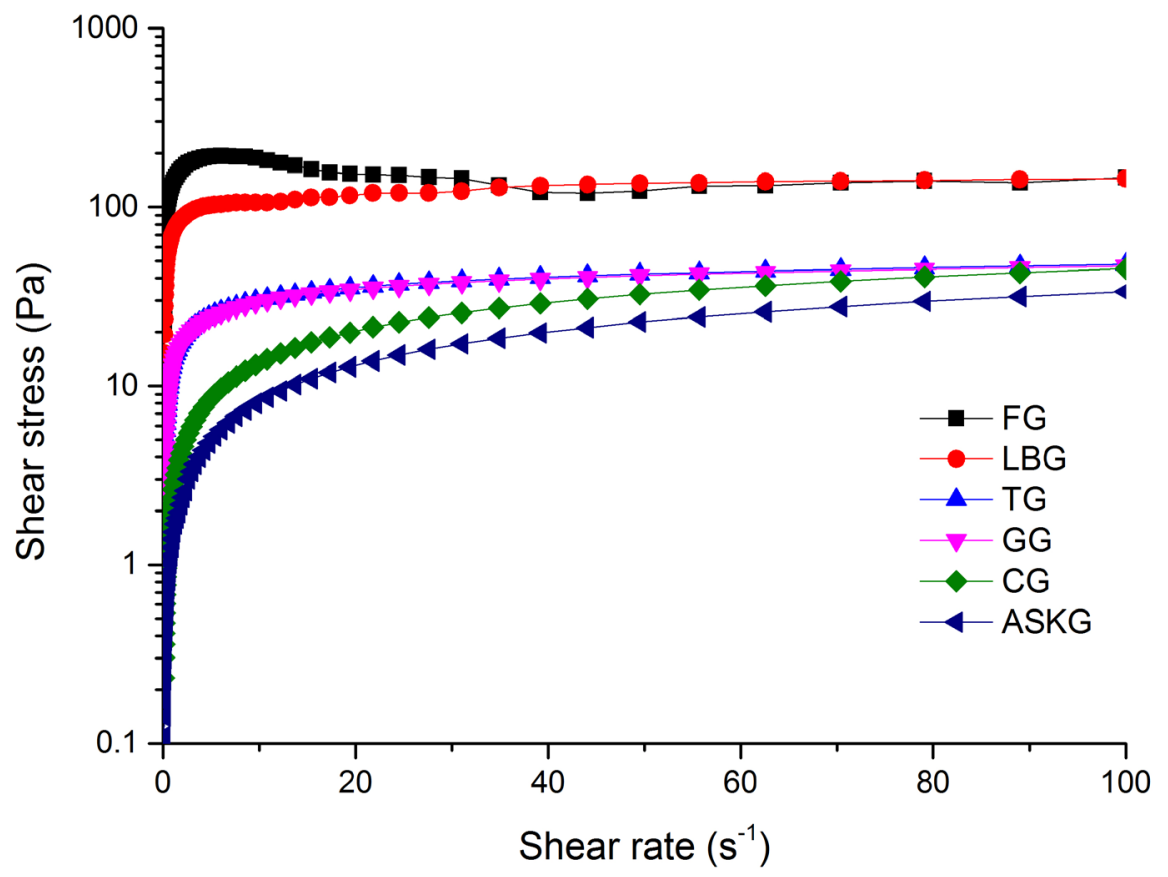

Figure 2. Shear stress flow behavior for six gum solutions versus shear rate ramps (1\% $\left.\mathrm{w} / \mathrm{w}, 25^{\circ} \mathrm{C}\right)$. 
Table 1. Power law parameters of apparent viscosity.

\begin{tabular}{cccc}
\hline Variety & $\mathrm{K}$ & $\mathrm{n}$ & $\mathrm{R}^{2}$ \\
\hline Flaxseed Gum & 15.046 & 0.283 & 0.9579 \\
Locust Bean Gum & 11.577 & 0.308 & 0.9664 \\
Tamarind Gum & 12.87 & 0.497 & 0.9892 \\
Guar Gum & 1.671 & 0.466 & 0.9876 \\
Cassia Gum & 0.468 & 0.731 & 0.9966 \\
Artemisia Sphaerocephala Krasch Gum & 0.102 & 0.925 & 0.9915 \\
\hline
\end{tabular}

and the highest $n$ value, this is to say that the apparent viscosity of ASKG has little changes with increasing shear rate.

\subsection{The Effects of Concentration, Temperature, $\mathrm{PH}$, Salt on apparent Viscosity}

Rheological behaviors are directly related to the structural features. The mass fraction plays a vital role affecting the apparent viscosity of six gums. As can be seen from Figure 3, the apparent viscosity of all six plant-based seed gums increases a lot as the mass fraction goes up, which could be explained that the increase in mass fraction strengthened hydrogen bond force between molecules and enhanced the fluid movement resistance. Therefore, the viscosity of six gums rose with the increase of mass faction at same shear rate. What shown in Figure 3 could be divided into three groups (Group 1, Group 2, Group3), which is consistent with the study of flow curves above. It can be inferred that the structural features made a great contribution to this phenomenon.

As the concentration of flaxseed gum and locust bean gum is less than $0.3 \%$, its viscosity keeps invariable with raising shear rate exhibiting the characteristics of Newtonian fluid (Figure 3(a), Figure 3(b)). While the concentration is higher than $0.3 \%$, the apparent viscosity decreased with the shear rate increasing showing the pseudoplasticity of shear thinning. However, for guar gum and tamarind gum (Figure 3(c), Figure 3(d)), they appear the trait of Newtonian fluid when the concentration is under 0.5\%. For cassia gum and Artemisia Sphaerocephala Krasch gum (Figure 3(e), Figure 3(f)), the viscosity of all different concentrations has barely changed with shear rate.

The relationship between apparent viscosity and temperature of six types of gums is shown in Figure 4, which clearly shows that temperature has a significant effect on the apparent viscosity of different gums. As demonstrated in Figure 4, the apparent viscosity of six gums decreases with close rate at different extent as the temperature goes up. This can be explained that the increase of temperature has intensified the molecular Brownian motion, which generated the space between molecules expanded as well as more difficult to form network structure. Consequently, the apparent viscosity has been reduced. The apparent viscosity of Flaxseed gum and Locust bean gum has little changes with increasing temperature; this is to say they have better thermal stability, which could be 


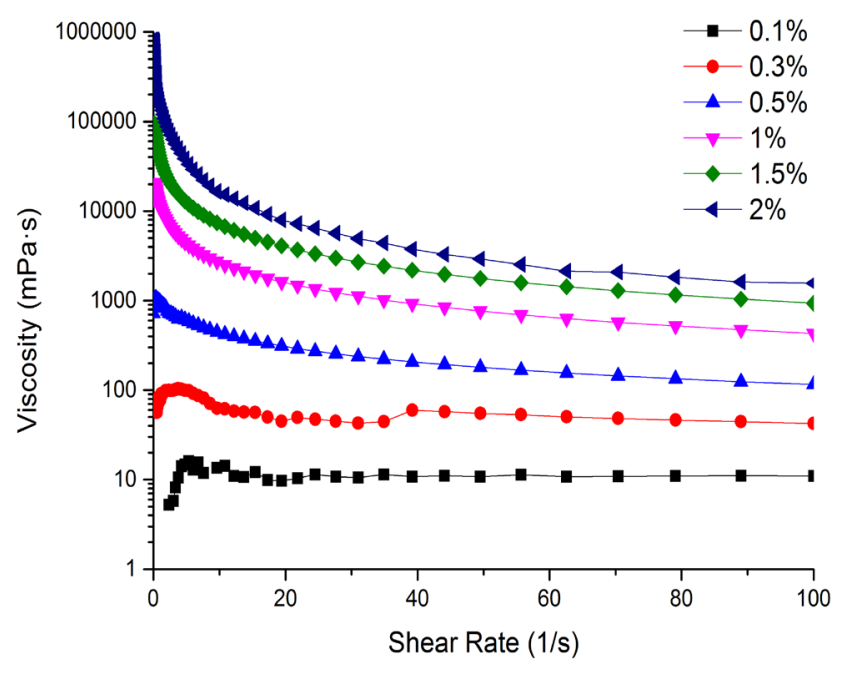

(a)

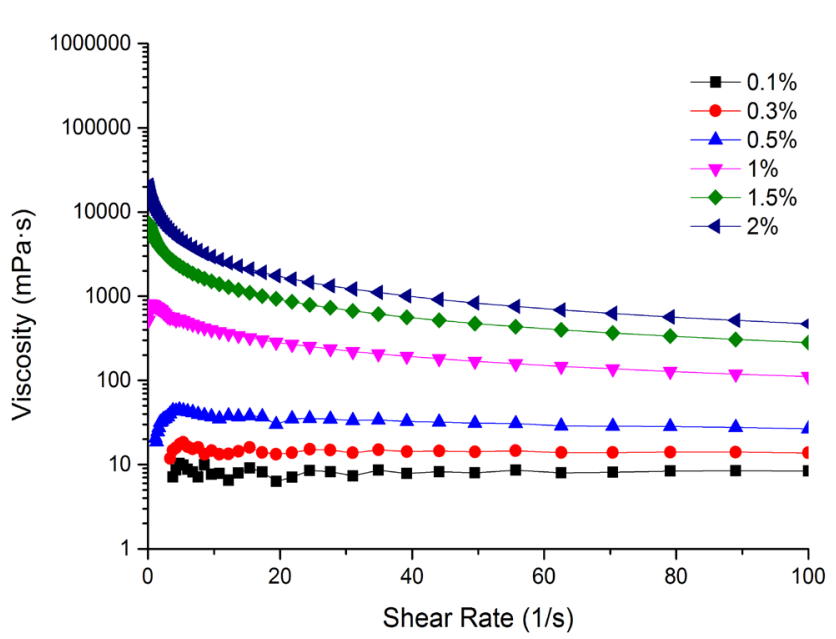

(c)

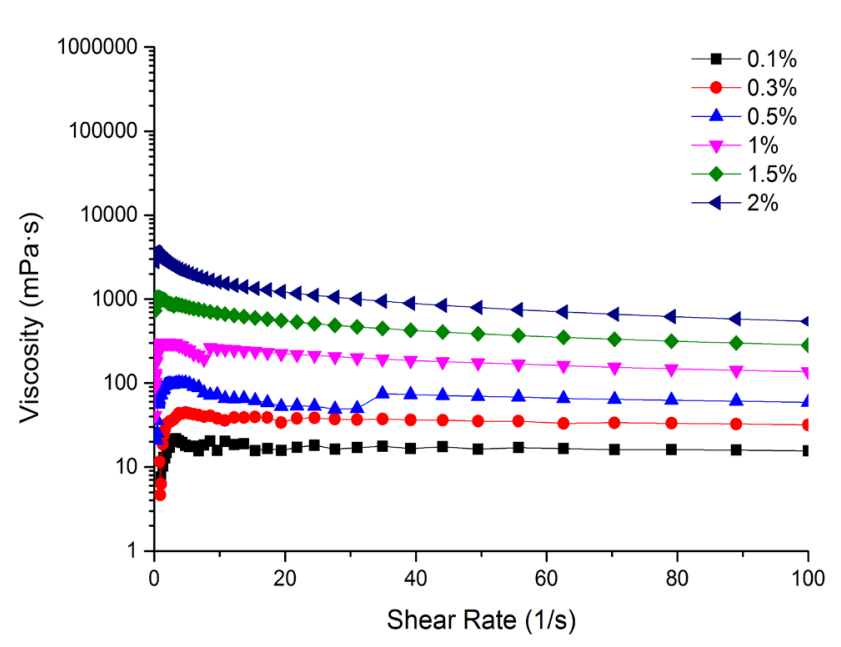

(e)

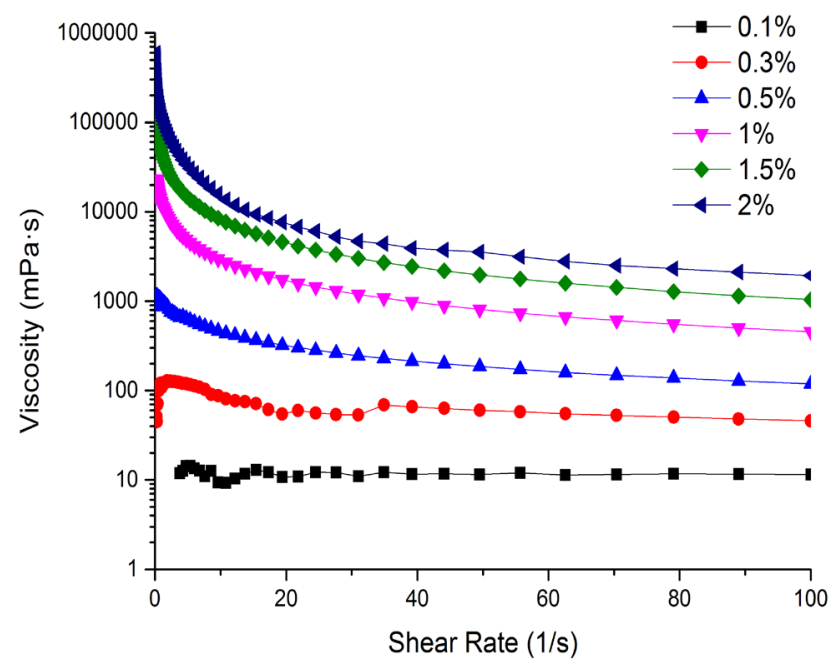

(b)

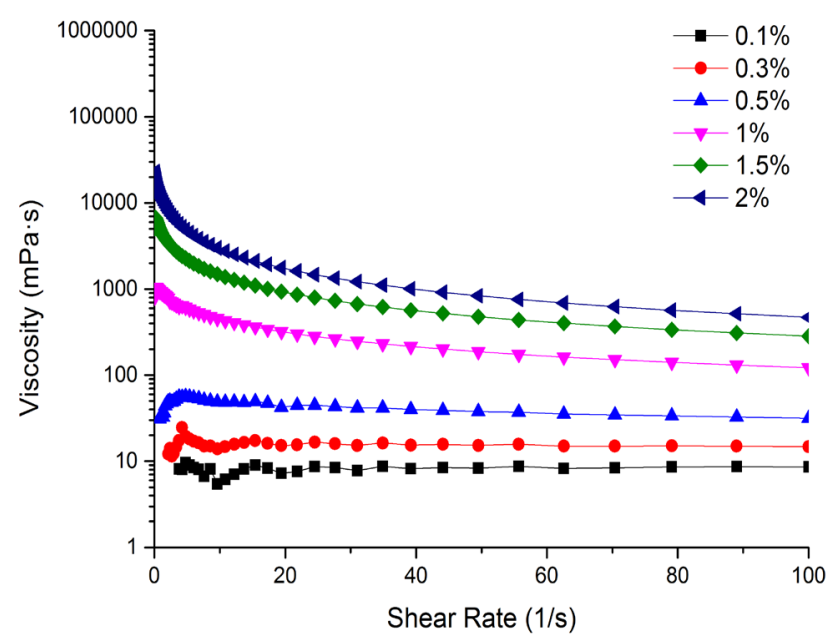

(d)

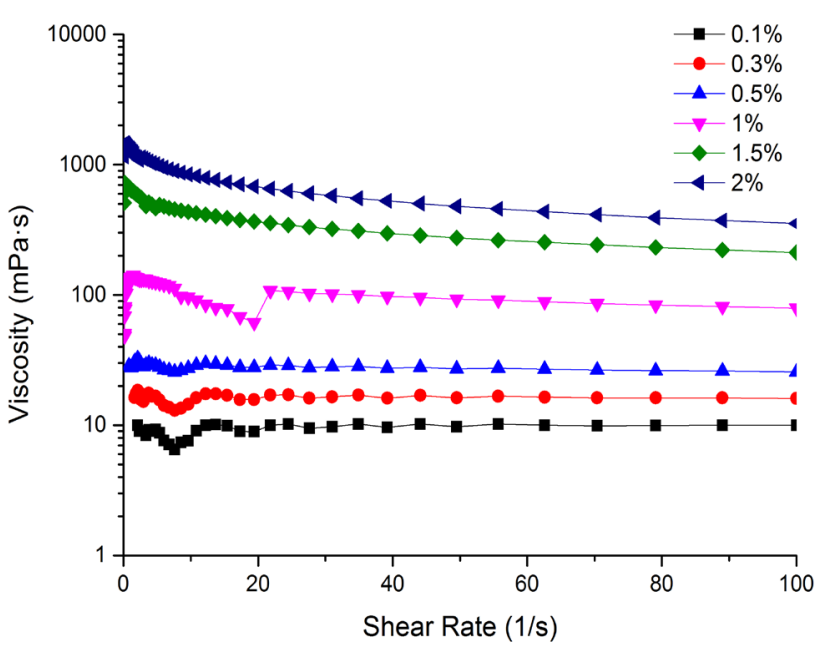

(f)

Figure 3. Effect of different concentration on apparent viscosity of six plant-based seed gums. ((a) Flaxseed gum; (b) Locust bean gum; (c) Guar gum; (d) Tamarind gum; (e) Cassia gum; (f) Artemisia Sphaerocephala Krasch gum. Group 1-((a),(b)), Group 2-((c),(d)), Group 3-((e),(f))). 


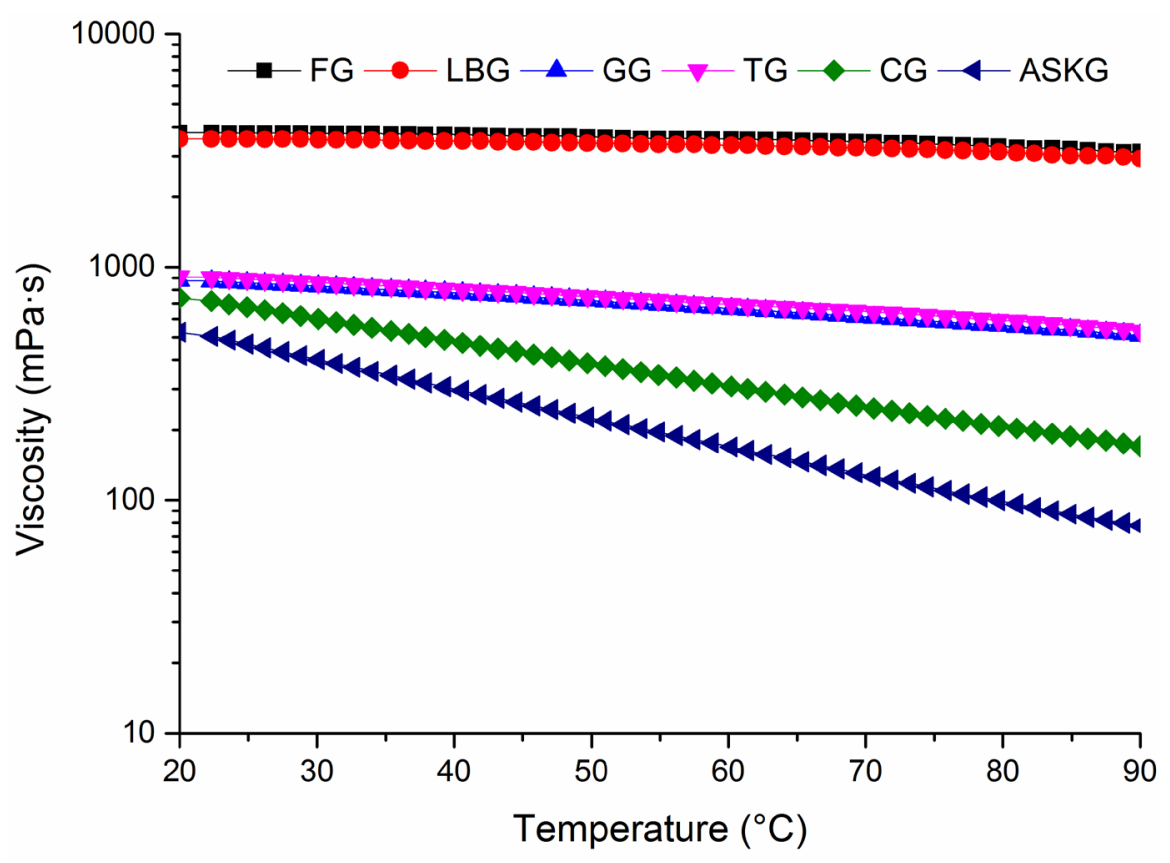

Figure 4. Effect of temperature on apparent viscosity of six plant-based seed gums.

Table 2. Arrhenius equation parameters of apparent viscosity.

\begin{tabular}{ccccccc}
\hline & $\begin{array}{c}\text { Flaxseed } \\
\text { Gum }\end{array}$ & $\begin{array}{c}\text { Locust } \\
\text { Bean Gum }\end{array}$ & $\begin{array}{c}\text { Tamarind } \\
\text { Gum }\end{array}$ & $\begin{array}{c}\text { Guar } \\
\text { Gum }\end{array}$ & Cassia Gum & $\begin{array}{c}\text { Artemisia Sphaerocephala } \\
\text { Krasch Gum }\end{array}$ \\
\hline $\mathrm{Ea}(\mathrm{kcal})$ & 1.37 & 1.44 & 2.15 & 2.41 & 3.71 & 4.30 \\
$\mathrm{R}^{2}$ & 0.9906 & 0.9930 & 0.9978 & 0.9961 & 0.9996 & 0.9946 \\
\hline
\end{tabular}

applied to food products with high demand for little viscosity changes at a wide range of temperature. Compared with FG and LBG, Guar gum and Tamarind gum have worse thermal stability. The apparent viscosity of Artemisia Sphaerocephala Krasch gum and Cassia gum had been affected severely with the change of temperature.

The flow activation energies (Ea) of six plant-based seed gums are calculated by the equation $\log \eta=\log \eta_{0}+E a / R T$. Ea and $\mathrm{R}^{2}$ are showed in Table 2 . The flow activation energies of six plant-based seed gums were different significantly. A higher Ea means a more rapid change in viscosity with temperature [19]. As can be seen in Table 2, Artemisia Sphaerocephala Krasch gum has the largest flow activation energy, which illustrates that the apparent viscosity of ASKG can be affected easily with the change of temperature. This can be demonstrated that ASKG is a complex colloidal mixture and with the increase of temperature, the forces between molecules were destroyed contributing to the rapid decrease in viscosity.

The effect of $\mathrm{pH}$ on the steady-shear viscosity is shown in Figure 5. From the figure, it is clear that $\mathrm{pH}$ has a various impact on apparent viscosity of six plant-based gums. The flaxseed gum solution showed the highest apparent viscosity at $\mathrm{pH} 4$, and then decreased gradually (Figure 5(a)). The apparent viscosity of locust 


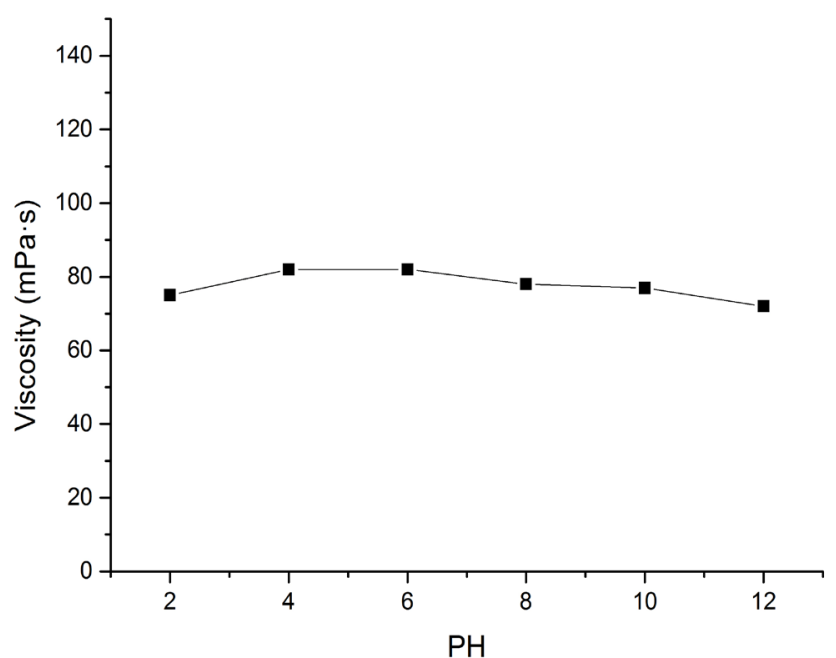

(a)

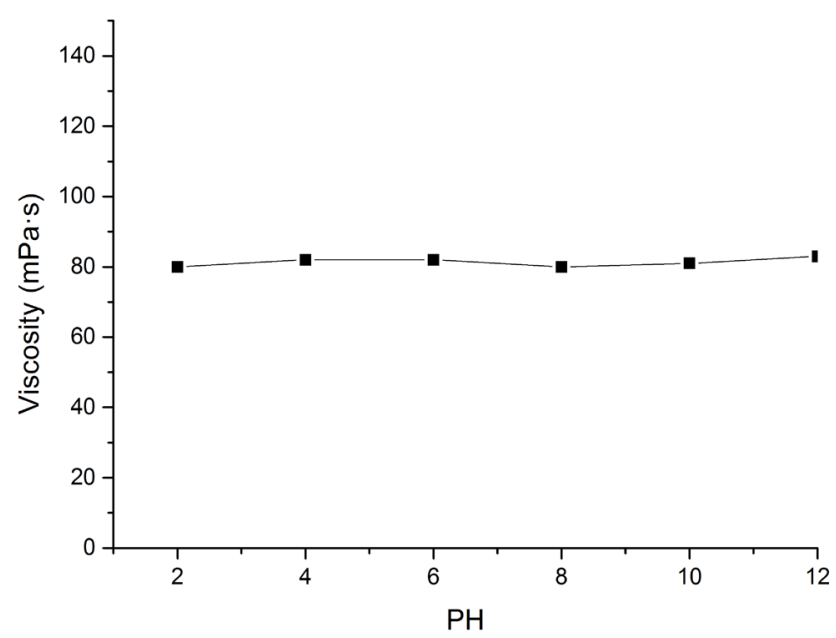

(c)

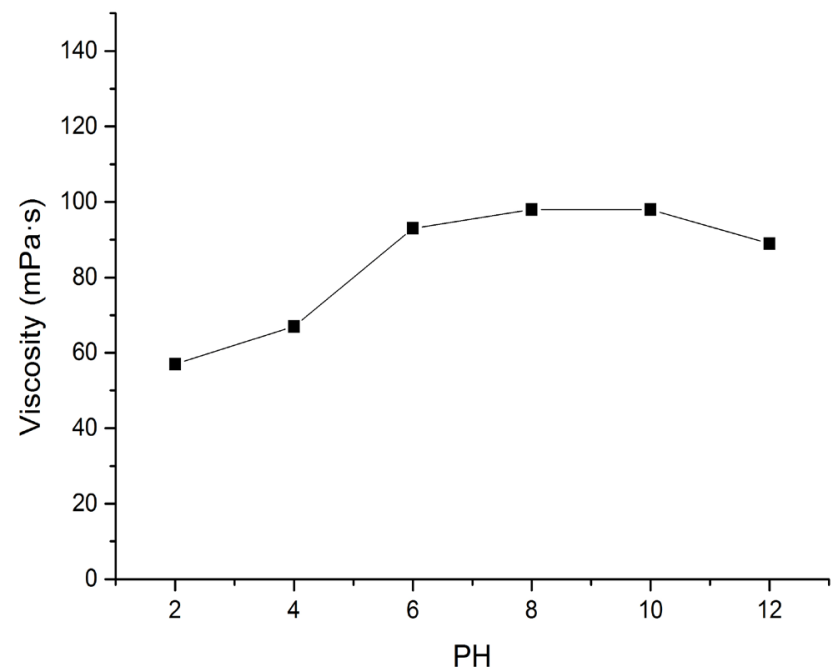

(e)

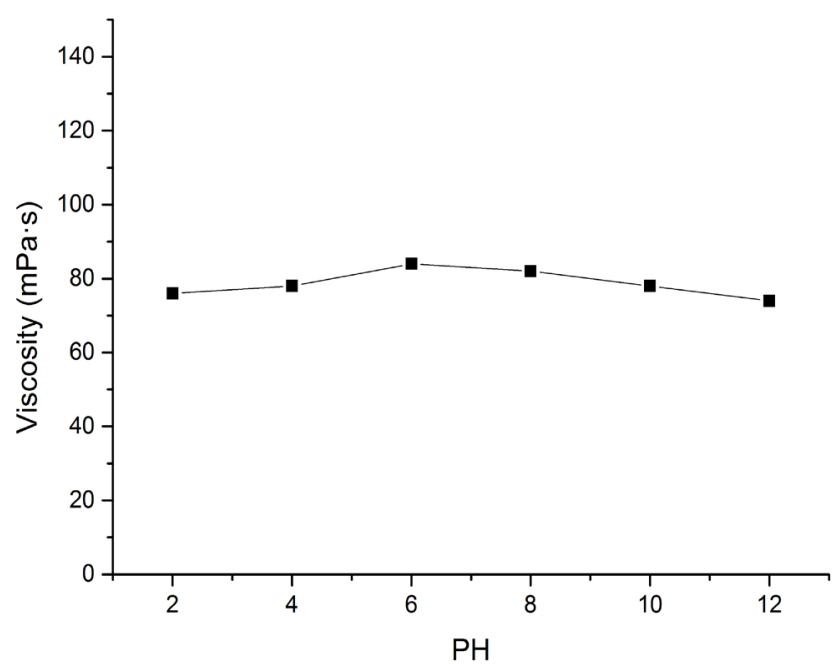

(b)

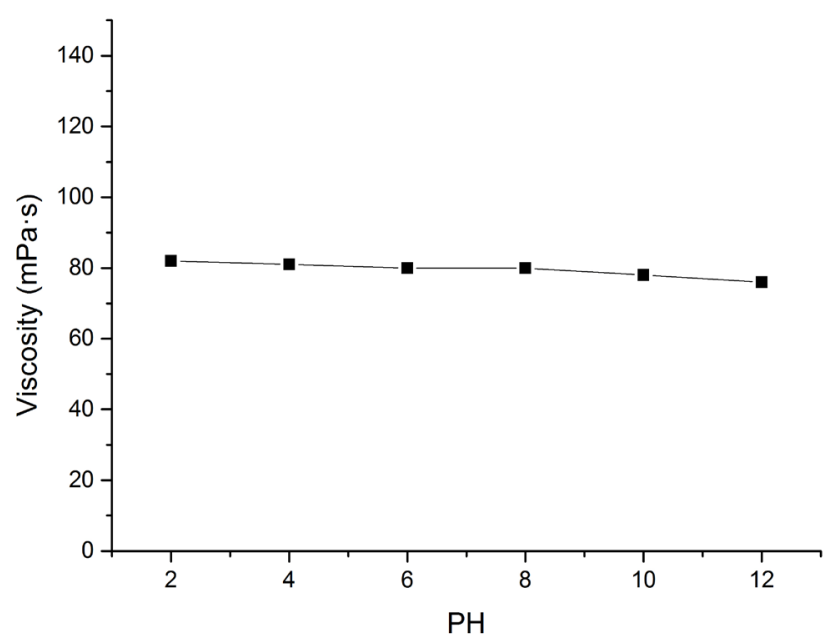

(d)

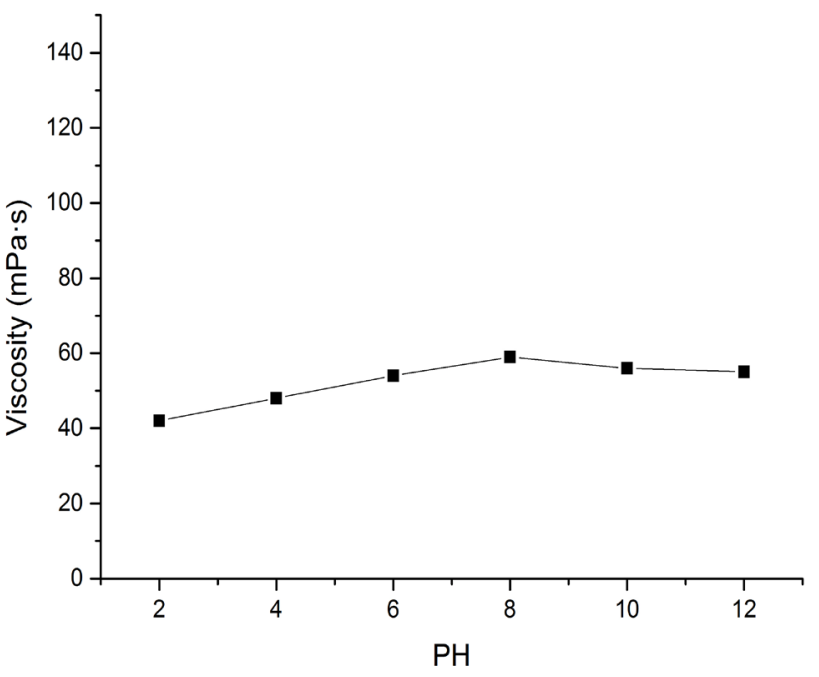

(f)

Figure 5. Effect of PH on apparent viscosity of six plant-based seed gums. ((a) Flaxseed gum; (b) Locust bean gum; (c) Guar gum; (d) Tamarind gum; (e) Cassia gum; (f) Artemisia Sphaerocephala Krasch gum). 
bean gum goes up firstly then declined reaching its peak at pH 6 (Figure 5(b)). For Guar gum and Tamarind gum, $\mathrm{pH}$ has a little effect on their apparent viscosity which shows they possess better property of resisting acid and alkali (Figure 5(c), Figure 5(d)). The effect of $\mathrm{pH}$ on Cassia gums viscosity is obvious compared with other gums (Figure 5(e)). The viscosity of Cassia in terms of $\mathrm{pH}$ $6-12$ is much higher than $\mathrm{pH} 2-6$. We assume with the decrease of $\mathrm{pH}$, the concentration of $\mathrm{H}+$ in the solution getting escalated, the combination between $\mathrm{H}+$ and anionic groups reduced the dissociation of polymer resulting in weaker charge rejection, macromolecular chain curl and solution viscosity decrease. The change of $\mathrm{pH}$ also has limited impact on the apparent viscosity of ASKG (Figure 5(f)), which is consistent with previous study [20]. On average, all plant-based seed gums have an advantage of resisting acid and alkali except Cassia gum.

The effect of salt type $\left(\mathrm{NaCl} \& \mathrm{CaCl}_{2}\right)$ on rheological properties of six plantbased seed gums was investigated and the experimental results regarding the effect on apparent viscosity are shown in Figure 6. In general, the apparent viscosity of six gums goes down with the increase of salt concentration, especially for CG and ASKG (Figure 6(e), Figure 6(f)). This may be due to the internal structure of CG and ASKG were damaged with the addition of salt. It should be noted that the variety of salt has different impact on each gum. The specific mechanism of interaction between salt and gum solutions need be investigated further.

\subsection{Dynamic Measurement Analysis}

The region that complex modulus $\mathrm{G}^{*}$ does keep consistent with the oscillation changes is named viscosity region [21]. $2 \%$ strain was used to determine the rheological properties of six gum samples. All mechanical spectra ( $G^{\prime}, G^{\prime \prime}$ function of temperature sweep) of oscillatory dynamic tests for $2 \%$ gum solutions are represented in Figure 7. As can be observed, all of the dynamic storage modulus $\mathrm{G}^{\prime}$, and the loss modulus G" show a dependency on the temperature. Both of them showed a downward trend in the wake of the increase of temperature. At the range of temperature from $20^{\circ} \mathrm{C}$ to $90^{\circ} \mathrm{C}$, the Storage modulus $\mathrm{G}^{\prime}$ of flaxseed gum and locust bean gum always superior to Loss modulus $\mathrm{G}^{\prime \prime}$ according to the value of $\tan \delta$, which means that the elastic response to temperature sweep is continuously higher than the viscosity response. In this case, the system behaves as a solid. However, the Storage modulus $\mathrm{G}^{\prime}$ of guar gum and tamarind gum is higher firstly at $20^{\circ} \mathrm{C}-65^{\circ} \mathrm{C}$ than Loss modulus $\mathrm{G}^{\prime \prime}$, then become lower at the range of $65^{\circ} \mathrm{C}-90^{\circ} \mathrm{C}$.this is to say that the mucilage solution system of CG and TG show changeable viscosity properties along with the change of temperature. The $\tan \delta$ value of Cassia gum and Artemisia Sphaerocephala Krasch gum is always above 1 , which indicates that at this range of temperature and mucilage concentrations, mucilage solutions will show mainly viscous properties instead of an obvious tendency to form a gel.

Figure 8 shows the variation in storage modulus $G^{\prime}$ and Loss modulus $G^{\prime \prime}$ 


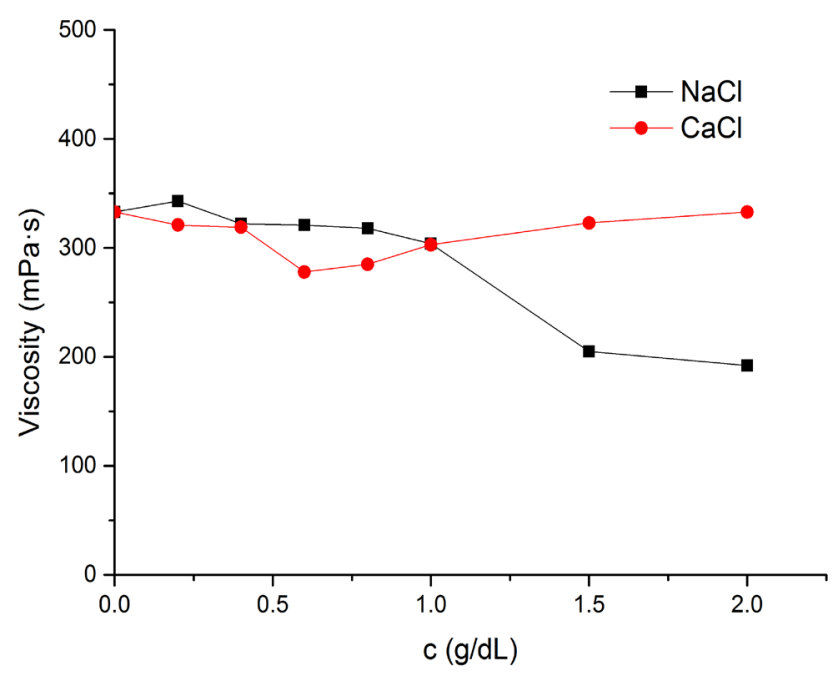

(a)

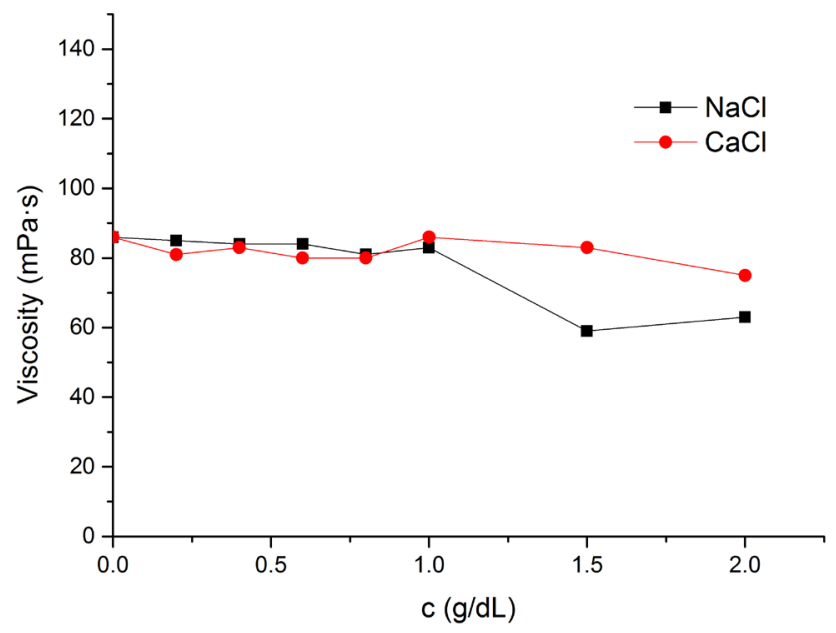

(c)

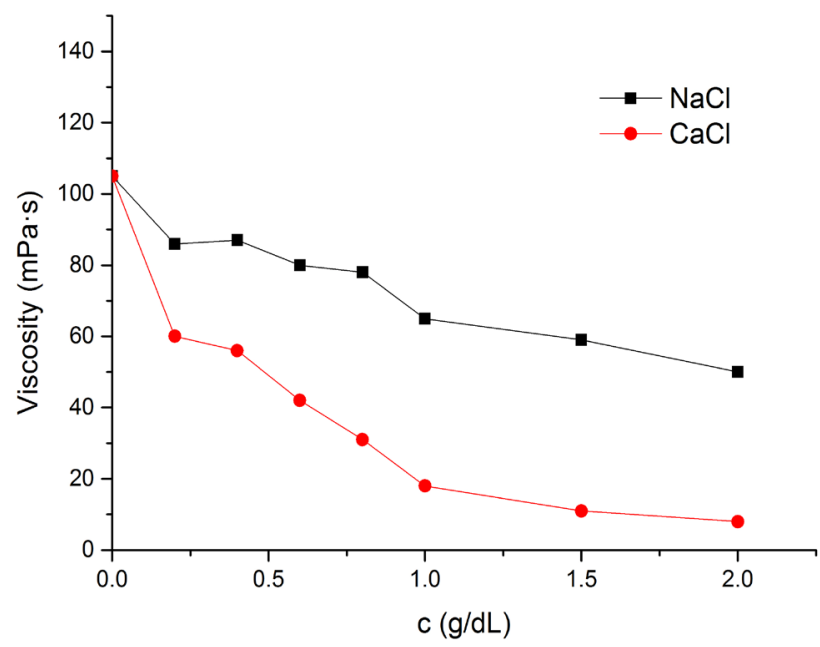

(e)

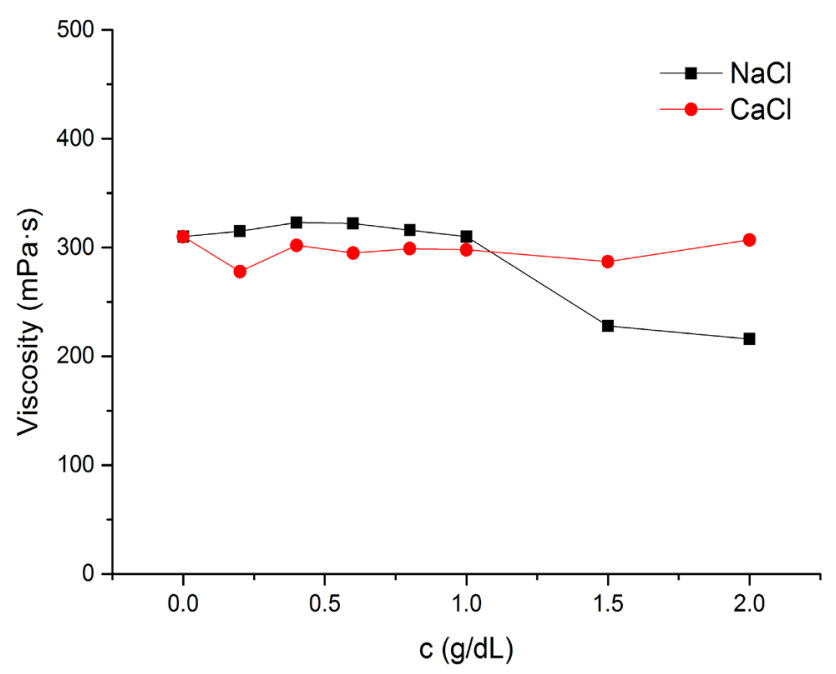

(b)

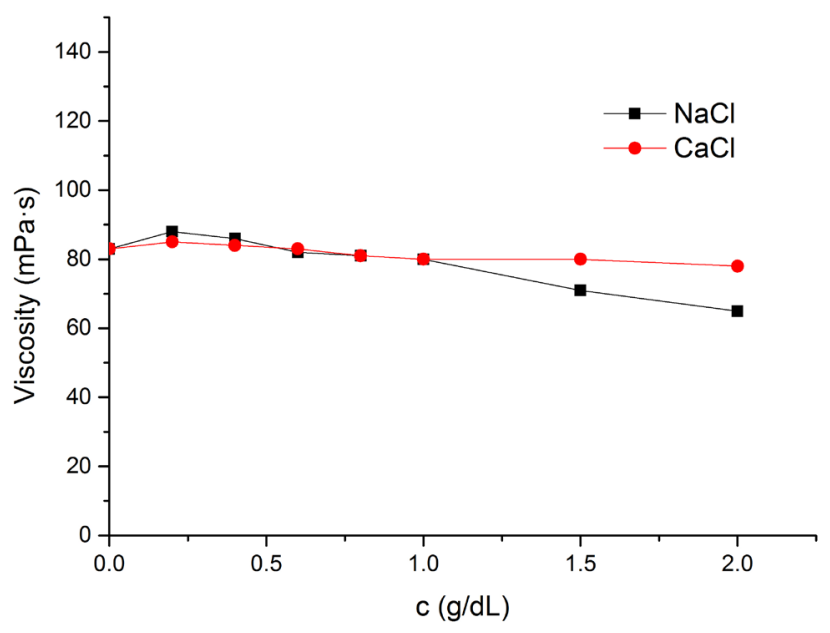

(d)

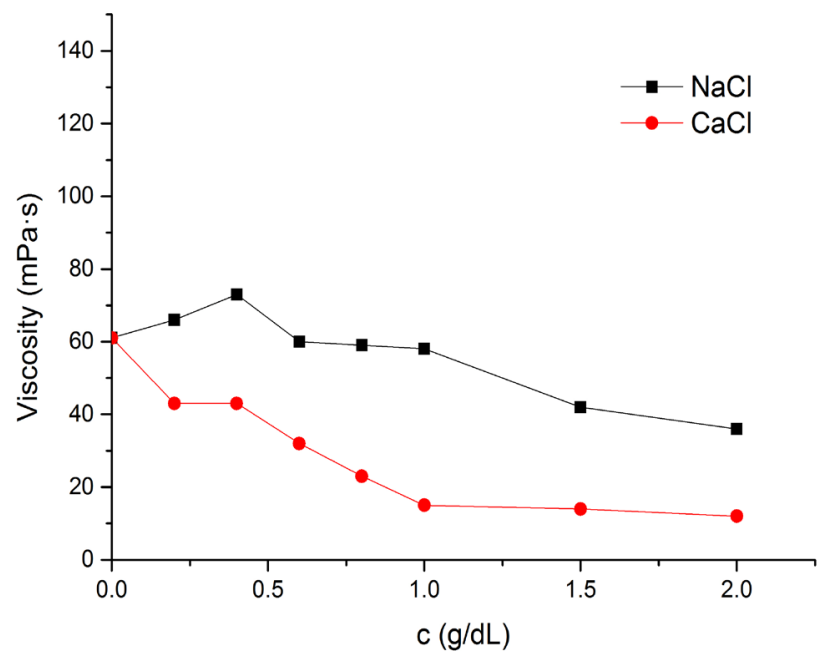

(f)

Figure 6. Effect of Salt on apparent viscosity of six plant-based seed gums. ((a) Flaxseed gum; (b) Locust bean gum; (c) Guar gum; (d) Tamarind gum; (e) Cassia gum; (f) Artemisia Sphaerocephala Krasch gum). 

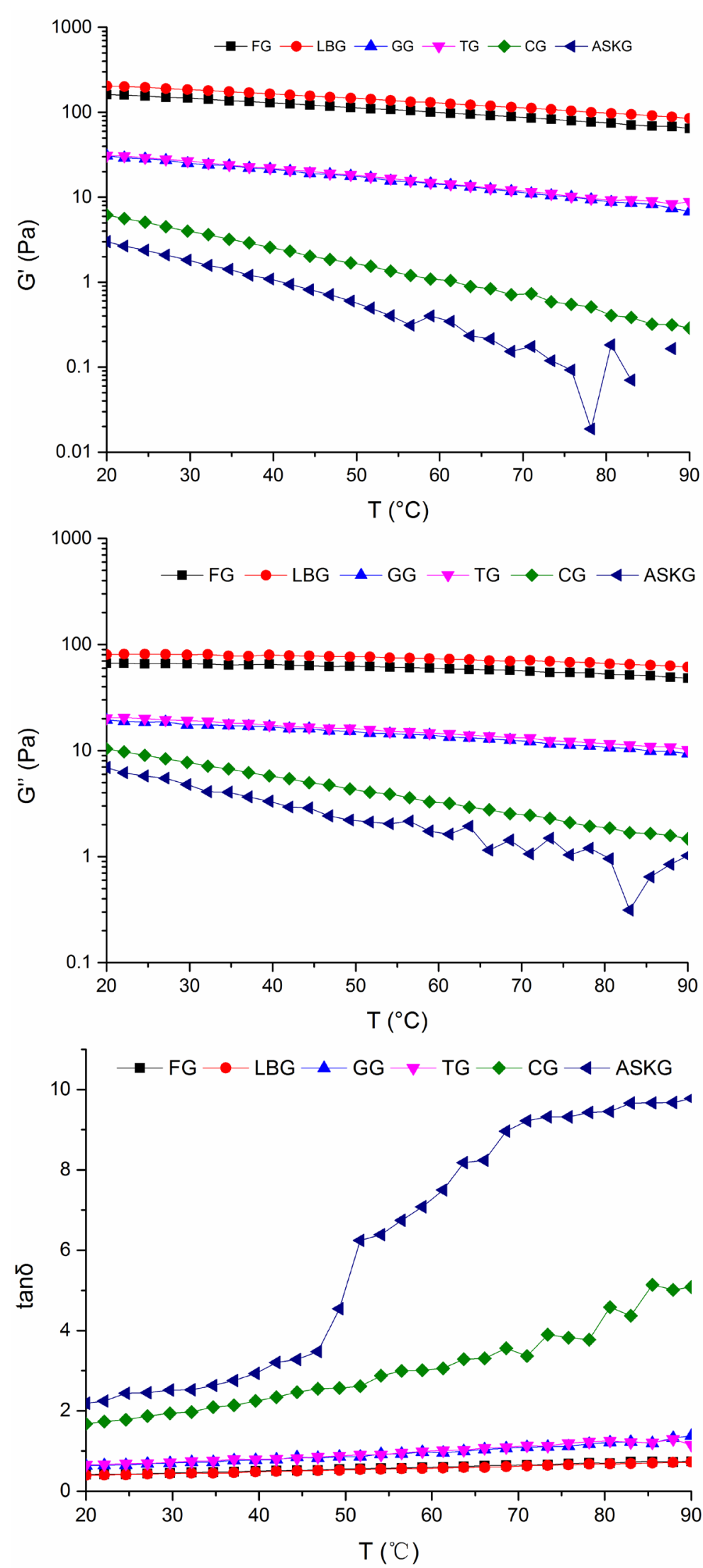

Figure 7. Temperature sweep (G', G", $\tan \delta$ ) of six plant-based seed gums. 

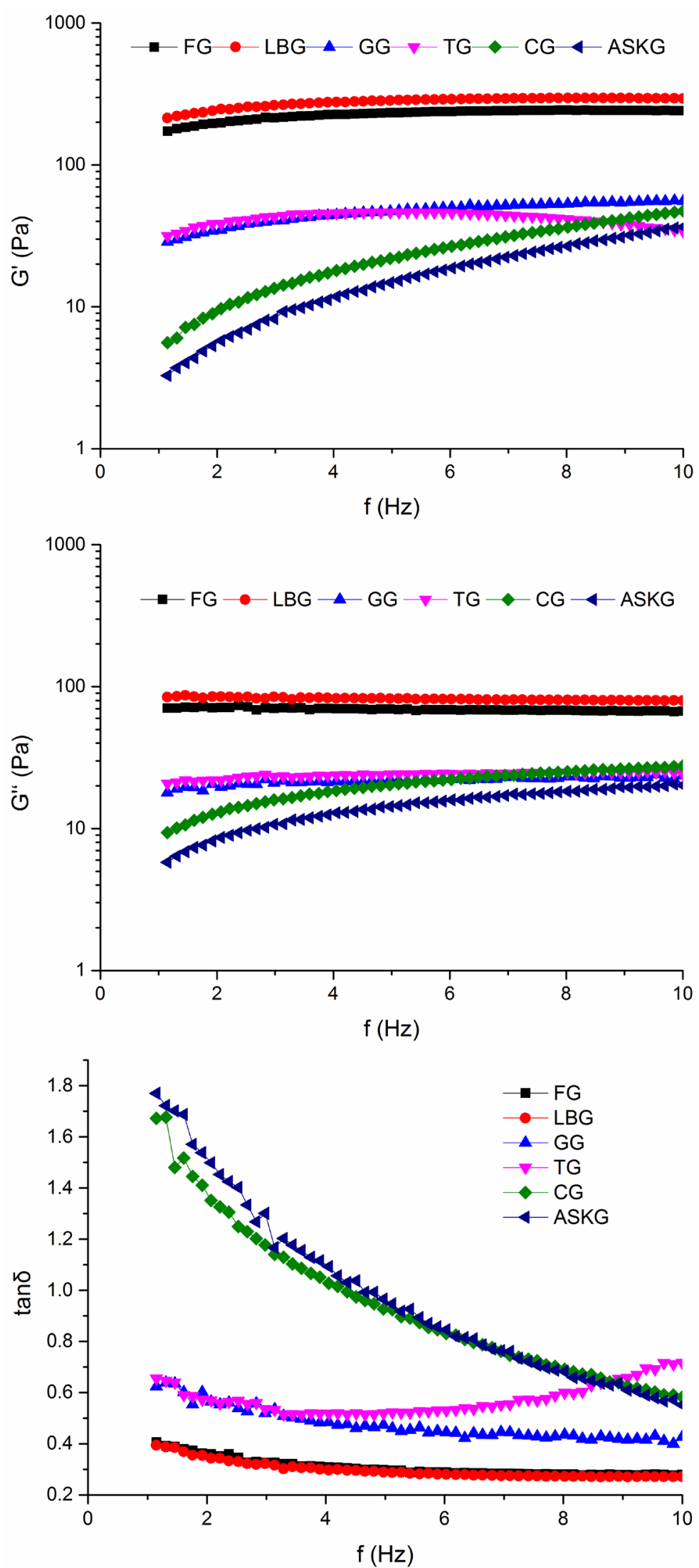

Figure 8. Frequency sweep (G', G", $\tan \delta$ ) of six plant-based seed gums. 
with frequency at $25^{\circ} \mathrm{C}$ for $2 \%$ mucilage solutions. It can be noticed that the elastic modulus $\mathrm{G}^{\prime}$ for four gums (flaxseed gum, locust bean gum, guar gum and Tamarind gum) remains higher than the viscous modulus $G^{\prime \prime}\left(G^{\prime}>G^{\prime \prime}\right)$, which means that the mucilage solutions weak typical physical gel characteristics than viscosity properties. This behavior is probably dependent on mucilage concentration. But it has a different impact on the mucilage solutions of CG and ASKG. The Storage modulus G' is higher than Loss modulus G" at low frequency, then a cross-over appears at $4 \mathrm{~Hz}\left(\mathrm{G}^{\prime}=\mathrm{G}^{\prime \prime}\right)$, where the system reverses subsequently the G' become lower than $G^{\prime \prime}$, which means that the mucilage solutions behave as a solid at low frequency and turns liquid in the end.

The variation in storage modulus modulus G' and Loss modulus G" with time at $25^{\circ} \mathrm{C}$ for $2 \%$ mucilage solutions are shown in Figure 9. It is shown that the elastic modulus $\mathrm{G}^{\prime}$ and viscous modulus $\mathrm{G}$ " has no changes with time increase, which means all six mucilage solutions are not time-dependent fluids. The behaviors are consistent with the results of steady-state rheology Analysis.

\section{Conclusions}

We have investigated the rheological behavior of six mucilage solutions from plant-based seed. Steady-shear viscosity measurements showed all the samples have a non-Newtonian shear-thinning behavior at different levels, which could be correlated to the shear rate by the power law model. We found that they could be subdivided into three different types according to the changes of viscosity with the increasing shear rate. The mass fraction made a great contribution to viscosity. Mucilage viscous solutions of all six gums were found obviously temperature-dependent and the apparent viscosity of six gums decreases with close rate at different extent as the temperature goes up. All mucilage solutions possessed better acid-proof and alkali-proof advantages except Cassia gum. A dependence of apparent viscosity with salt was also found. The apparent viscosity of six gums goes down with the increase of salt concentration, especially for CG and ASKG.

The dynamic flow properties in the linear viscosity region, as a function of temperature and frequency, were studied. Both elastic modulus $G^{\prime}$ and viscous modulus G" behaviors were found to be dependent on temperature and frequency. The Storage modulus G' of flaxseed gum and locust bean gum is always superior to Loss modulus $G^{\prime \prime}$, which means that the elastic response to temperature sweep is continuously higher than the viscosity response. The Storage modulus G' of guar gum and tamarind gum is higher firstly than Loss modulus G", then become lower. However, the $\tan \delta$ value of Cassia gum and Artemisia Sphaerocephala Krasch gum is always above 1, which indicates that mucilage solutions will show mainly viscous properties instead of an obvious tendency to form a gel. The elastic modulus G' for four gums (flaxseed gum, locust bean gum, guar gum and Tamarind gum) remains higher with the change of frequency than the viscous modulus G" (G'> G"). For CG and ASKG, the Storage modulus G' is higher 

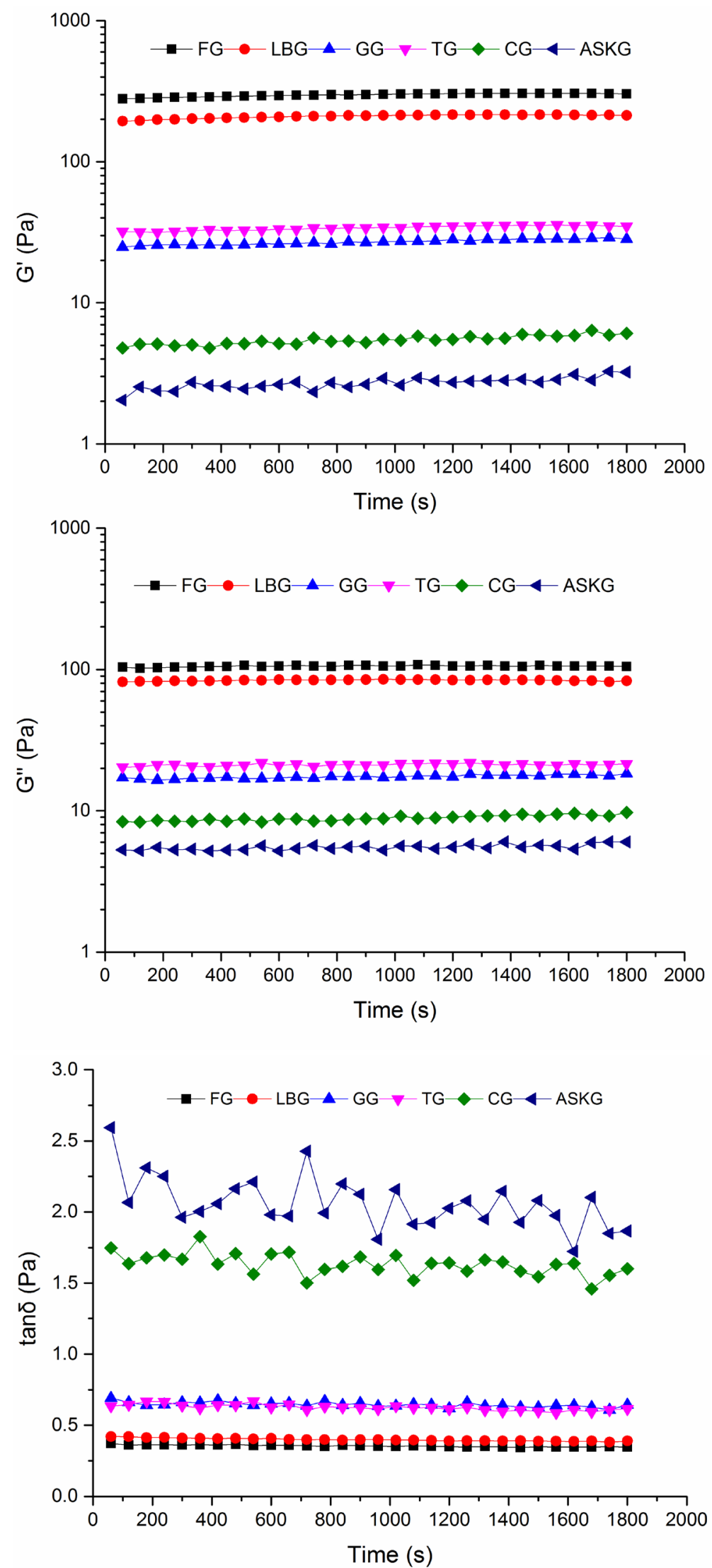

Figure 9. Time dependent behavior of six plant-based seed gums. 
than Loss modulus G" at low frequency, then a cross-over appears at $4 \mathrm{~Hz}\left(\mathrm{G}^{\prime}=\right.$ G"). All six mucilage solutions are not time-dependent fluids

Overall, what we have found above could support the application of plant-based seed gums in food industry; hence it is required in further work to study the application in different food products as well as the mechanisms.

\section{Acknowledgements}

This study was supported by the project sponsored by National Natural Science Foundation of China (No. 31571865) and Qingdao Technology Benefiting Project (No.15-9-2-107-NSH).

\section{References}

[1] Rana, V., Rai, P., Tiwary, A.K., Singh, R.S., Kennedy, J.F. and Knill, C.J. (2011) Modified Gums: Approaches and Applications in Drug Delivery. Carbohydrate Polymers, 83, 1031-1047. https://doi.org/10.1016/j.carbpol.2010.09.010

[2] Williams, P.A., Phillips, G.O., Phillips, G.O. and Williams, P.A. (2009) Introduction to Food Hydrocolloids. Handbook of Hydrocolloids, 70, 1-22. https://doi.org/10.1533/9781845695873.1

[3] Williams, P.A. and Phillips, G.O. (2003) Gums Food Uses. Encyclopedia of Food Sciences \& Nutrition, 23, 3001-3007. https://doi.org/10.1016/B0-12-227055-X/00574-5

[4] Laaman, T.R. (2010) Hydrocolloids: Fifteen Practical Tips. Hydrocolloids in Food Processing. Wiley-Blackwell, Hoboken.

[5] Mirhosseini, H. and Amid, B.T. (2012) A Review Study on Chemical Composition and Molecular Structure of Newly Plant Gum Exudates and Seed Gums. Food Research International, 46, 387-398. https://doi.org/10.1016/j.foodres.2011.11.017

[6] He, L. (2013) Economic Contribution of Gum and Resin Resources to Household Livelihoods in Selected Regions and the National Economy of Ethiopia. Ethnobotany Research \& Applications, 11, 273-288.

[7] Glicksman, M. (1969) Gum Technology in the Food Industry/Martin Glicksman. Vol. 11, 895-902.

[8] Chen, H.H., Xu, S.Y. and Wang, Z. (2006) Gelation Properties of Flaxseed Gum. Journal of Food Engineering, 77, 295-303.

[9] Shak, K.P.Y. and Wu, T.Y. (2016) Synthesis and Characterization of a Plant-Based Seed Gum via Etherification for Effective Treatment of High-Strength Agro-Industrial Wastewater. Chemical Engineering Journal, 307, 928-938.

[10] Barbosacánovas, G.V. and Ma, L. (1993) Review: Rheological Properties of Food Gums and Food Gum Mixtures. Revista Espanola De Ciencia Y Tecnologia De Alimentos, 33, 133-163.

[11] Wang, S., He, L., Guo, J., Zhao, J. and Tang, H. (2015) Intrinsic Viscosity and Rheological Properties of Natural and Substituted Guar Gums in Seawater. International Journal of Biological Macromolecules, 76, 262.

[12] Haddarah, A., Bassal, A., Ismail, A., Gaiani, C., Ioannou, I., Charbonnel, C., et al. (2014) The Structural Characteristics and Rheological Properties of Lebanese Locust Bean Gum. Journal of Food Engineering, 120, 204-214.

[13] Mazza, G. and Biliaderis, C.G. (2010) Functional Properties of Flax Seed Mucilage. Journal of Food Science, 54, 1302-1305. 
https://doi.org/10.1111/j.1365-2621.1989.tb05978.x

[14] Liu, B.J. and Min, J. (2008) Rheological Properties of Guar Gum for Printing. Textile Auxiliaries.

[15] Yong, W., Wang, L.J., Dong, L., Xue, J. and Mao, Z.H. (2009) Effects of Drying Methods on Rheological Properties of Flaxseed Gum. Carbohydrate Polymers, 78, 213-219.

[16] Bourbon, A.I., Pinheiro, A.C., Ribeiro, C., Miranda, C., Maia, J.M., Teixeira, J.A., et al. (2010) Characterization of Galactomannans Extracted from Seeds of Gleditsia Triacanthos and Sophora Japonica through Shear and Extensional Rheology: Comparison with Guar Gum and Locust Bean Gum. Food Hydrocolloids, 24, 184-192.

[17] Zhao, C., Zholkovskij, E., Masliyah, J.H. and Yang, C. (2008) Analysis of Electroosmotic Flow of Power-Law Fluids in a Slit Microchannel. Journal of Colloid \& Interface Science, 326, 503.

[18] Kaushik, P., Dowling, K., Adhikari, R., Barrow, C.J. and Adhikari, B. (2017) Effect of Extraction Temperature on Composition, Structure and Functional Properties of Flaxseed Gum. Food Chemistry, 215, 333-340.

[19] Medina-Torres, L., Fuente, B.D.L., Torrestiana-Sanchez, B. and Katthain, R. (2000) Rheological Properties of the Mucilage Gum (Opuntia Ficus Indica). Food Hydrocolloids, 14, 417-424.

[20] Liu, D.H. and Wen-Ying, G.U. (2006) Rheological Properties of Artemis Sphaerocephala Krasch Gum. Food Science, 27, 76-80.

[21] Vinod, V.T., Sashidhar, R.B., Sarma, V.U. and Vijaya Saradhi, U.V. (2008) Compositional Analysis and Rheological Properties of Gum Kondagogu (Cochlospermum Gossypium): A Tree Gum from India. Journal of Agricultural \& Food Chemistry, 56, 2199. https://doi.org/10.1021/jf072766p 